\title{
PENGARUH KOMPENSASI DAN BUDAYA ORGANISASI TERHADAP SEMANGAT KERJA KARYAWAN DI DAZZLE ACCESSORIES YOGYAKARTA
}

\author{
Hesty Wulandari \\ Fakultas Ekonomi Universitas Sarjanawiyata Tamansiswa \\ Email: wulandrhesty76@gmail.com
}

\begin{abstract}
Intisari
Tujuan penelitian ini adalah untuk mengetahui pengaruh kompensasi dan budaya organisasi terhadap karyawan di Dazzle Accessories Yogyakarta.Populasi dari penelitian ini adalah karyawan tetap di Dazzle Accessories Yogyakarta dengan jumlah karyawan 97. Teknik pengambilan sampel adalah sampel jenuh dengan mengambil semua sampel yaitu 97 karyawan. Metode pengumpulan data dengan kuesioner.Hasil penelitian menunjukkan bahwa kompensasi secara parsial tidak signifikan berpengaruh terhadap semangat kerja. Sedangkan budaya organisasi berpengaruh signifikan terhadap semangat kerja karyawan.

Kata kunci: kompensasi, budaya organisasi dan semangat kerja

Abstract

The purpose of this research is to know the influence of compensation and Cultural organization of employees at Dazzle Accessories Yogyakarta. The population of this research is permanent employees at Dazzle Accessories Yogyakarta with a total of 97 employees. Sampling techniques are saturated samples by taking all samples of 97 employees. Method of collecting data with questionnaires. Results showed that partial compensation did not significantly affect the morale of work. While organizational culture has a significant impact on employee morale.
\end{abstract}

Keywords: compensation, organizational culture and the spirit of work.

\section{PENDAHULUAN}

Adanya banyak peluang yang tersedia untuk membuka suatu usaha, peluang usaha aksesoris handphone dan komputer bisa dibilang terus terbuka. Peluang usaha untuk kategori aksesoris handphone memang selalu terbuka dan bahkan bisa dibilang terus meningkat seiring dengan semakin meluasnya kebutuhan akan handphone dimasyarakat saat ini.

Usaha aksesoris handphone dan komputer saat ini termasuk usaha yang unggul dan menjanjikan di Yogyakarta atau bahkan di beberapa wilayah di Indonesia. Hal ini disebabkan karna aksesoris handphone dan komputer juga termasuk barang yang dibutuhkan oleh orang banyak terutama remaja atau mahasiswa. Kebutuhan ini akan meningkat dari waktu ke waktu seiring dengan perkembangan model, kebutuhan akan aksesoris handphone dan komputer pun meningkat. Dan masuknya mahasiswa baru setiap tahunnya di Yogyakarta juga menajadi suatu keuntungan tersendiri jika membuka usaha ini. Banyak mahasiswa yang menginginkan alat elektronik mereka terlihat lebih menarik dan unik, karena hal tersebut yang di butuhkan adalah aksesoris untuk memperindah barang elektronik mereka.

Dazzle Accessories Yogyakarta telah berdiri sejak tahun 2005. Dazzle Accessories sampai saat ini sudah memiliki tiga cabang, dua toko berada di Yogyakarta dan satu toko berada di Semarang. Dazzle merupakan usaha yang bergerak dalam bidang penjualan aksesoris handphone dan komputer. Dazzle menjadi salah satu jujukan utama ketika orang butuh aksesoris handphone. Toko yang besar membuat nyaman, produk yang lengkap, dan harga yang terjangkau untuk semua orang termasuk mahasiswa menjadi alasan orang berbondong-bondong datang ke Dazzle Accessories Yogyakarta.

Seiring berkembangnya suatu usaha, maka semakin kompleks dan rumit pula pengelolaannya terutama dibagian sumber daya manusianya. Untuk itu diperlukan sistem 
manajemen yang mengelola hubungan antara perusahaan dengan sumber daya manusianya. Terutama mengenai tata kelola kompensasi untuk karyawan di perusahaan. Salah satu hal yang bisa dilakukan oleh perusahaan agar usahanya tetap berjalan dengan lancar dan sesuai rencana adalah dengan memberikan kompensasi kepada karyawannya, sehingga hubungan antara perusahaan dan sumber daya manusianya akan tetap terjalin dengan baik

Kompensasi memiliki pengaruh yang sangat penting dalam meningkatkan semangat kerja karyawan, seperti yang diketahui kompensasi adalah semua pendapatan yang diterima pegawai atau karyawan sebagai imbalan dari jasa dan pekerjaan yang diberikan pegawai atau karyawan kepada perusahaan (Hartatik, 2014).

Budaya organisasi adalah suatu sistem makna bersama yang dianut oleh semua anggotanya yang membedakan organisasi itu dengan organisasi yang lain (Robbins, 2012). Dalam rangka mewujudkan budaya organisasi yang cocok diterapkan pada sebuah organisasi, maka diperlukan adanya dukungan dan partisipasi dari semua anggota yang ada dalam lingkup organisasi tersebut. Tujuan penerapan budaya organisasi adalah agar seluruh individu dalam perusahaan mematuhi dan berpedoman pada sistem nilai keyakinan dan norma-norma yang berlaku dalam perusahaan atau organisasi tersebut.

\section{TINJAUAN PUSTAKA DAN PENGEMBANGAN HIPOTESIS Kompensasi}

Menurut Hasibuan (2012), kompensasi adalah semua pendapatan yang diterima karyawan yang berbentuk uang, barang langsung atau tidak langsung yang merupakan bentuk biaya yang harus dikeluarkan perusahaan dengan harapan memperoleh imbalan berupa prestasi kerja dari karyawan.

Menurut Hartatik (2014) mengatakan bahwa kompensasi merupakan bentuk penghargaan yang diberikan perusahaan kepada karyawanya baik dalam bentuk finansial maupun nonfinansial dalam bentuk barang dan jasa pelayanan agar karyawan merasa dihargai dalam melakukan tugas organisasi. Kompensasi bagi suatu perusahaan yang berorientasi pada profit merupakan salah satu faktor yang sangat penting untuk memelihara, mempertahankan dan menarik tenaga kerja untuk kepentingan perusahaan, kompensasi merupakan dorongan bagi para karyawan dalam bekerja dan juga dapat menjadi pemicu yang tinggi terhadap semangat kerja karyawan.

Kompensasi merupakan seluruh balas jasa yang diterima oleh karyawan dari perusahaan sebagai imbalan atas pekerjaan mereka di perusahaan dalam bentuk finansial atau non finansial dan menjadi tujuan utama karyawan.Penelitian yang dilakukan Satriadi, Wahyunie, Marlinda, \& Ilyas, (2018) dengan judul Pengaruh Kompensasi Terhadap Semangat Kerja Karyawan Ramayana Departement Store Cabang Kota Tanjungpinang, menunjukkan bahwa kompensasi berpengaruh secara signifikan dan positif terhadap semangat kerja karyawan..

H1: Kompensasi berpengaruh signifikan positif terhadap semangat kerja karyawan di Dazzle Accessories Yogyakarta

\section{Budaya Organisasi}

Menurut Mangkunegara (2005) budaya organisasi didefinisikan sebagai perangkat asumsi, nilai-nilai dan norma yang dikembangkan dalam organisasi yang dijadikan pedoman tingkah laku bagi anggotanya untuk mengatasi masalah adaptasi eksternal dan integrasi internal. Selain itu dengan adanya semangat kerja yang tinggi maka akan buat kinerja karyawan akan meningkat. Dalam mencapai tujuan perusahaan yakni melalui peningkatan kinerja yang optimal dengan penyesuaian kompensasi dan penciptaan budaya organisasi yang baik, maka mampu meningkatkan semangat kerja karyawan.

Budaya organisasi menurut Mangkunegara (2005) merupakan filosofi dasar organisasi yang memuat keyakinan, norma-norma dan nilai-nilai bersama yang menjadi karakteristik inti 
tentang bagaimana cara melakukan sesuatu dalam organisasi. Berdasarkan penelitian yang dilakukan Prijatna \& Cahyaningrum (2019) dengan judul Pengaruh Budaya Organisasi Terhadap Semangat Kerja Dengan Kepuasan Kerja Sebagai Variabel Mediasi (Studi Pada Perum Lembaga Penyelenggaraan Pelayanan Navigasi Penerbangan Indonesia Cabang Tarakan) dikemukakan bahwa budaya organisasi berpengaruh positif dan signifikan terhadap semangat kerja karyawan.

H2: Budaya Organisasi berpengaruh signifikan positif terhadap semangat kerja karyawan di Dazzle Accessories Yogyakarta

\section{Semangat Kerja}

Menurut Nitisemito (2010), semangat kerja adalah melakukan pekerjaan secara giat dan rajin, sehingga pekerjaan yang diharapkan lebih cepat terselesaikan danhasilnyapun lebih baik. Sedangkan menurut Alexander Leighten dalam Moekijat (2006:130) mendefinisikan semangat kerja sebagai kemampuan sekelompok orang untuk bekerja sama dengan giat dan konsekuen dalam mengejar tujuan bersama.

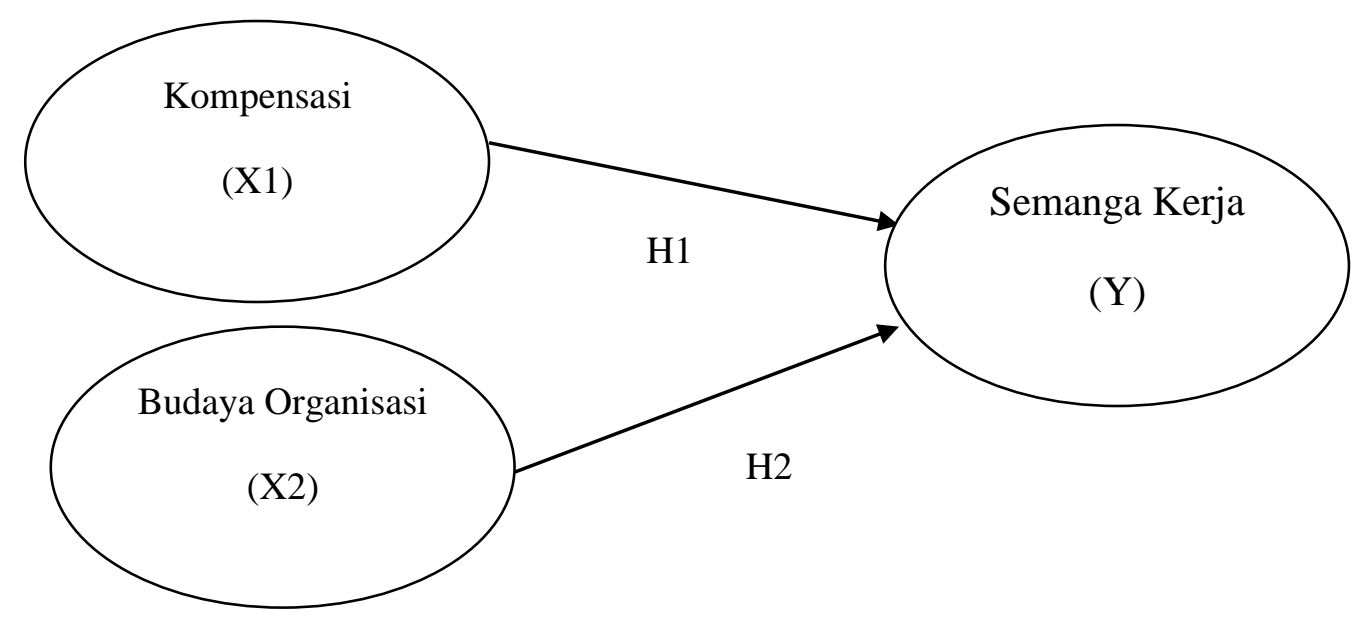

\section{Gambar 1. Kerangka Penelitian}

\section{METODE PENELITIAN}

Penelitian ini bersifat kuantitatifdan pengambilan datanya menggunakan kuesioner dan wawancara. Populasi dan sampel yang digunakan adalah seluruh karyawan tetap di Dazzle Accessories Yogyakarta. Pengambilan sampel menggunkan teknik Sampel Jenuh. Menurut Sugiyono (2014) metode sampel jenuh adalah teknik penentuan sampel bila semua anggota populasi digunakan menjadi sampel.

\section{HASIL DAN PEMBAHASAN \\ Karakter Responden}

Tabel 1 Karakteristik Responden

\begin{tabular}{ccc}
\hline Kategori & Frekuensi & Prosentase \\
\hline Jenis kelamin & & 48,5 \\
Laki-laki & 47 & 51,5 \\
Perempuan & 50 & \\
\hline Usia & & 40,2 \\
$21-25$ tahun & 39 & 53,6 \\
$26-30$ tahun & 52 & 3,1 \\
$31-35$ tahun & 3 & 3,1 \\
\hline
\end{tabular}




\begin{tabular}{ccc}
\hline & & \\
\hline Pendidikan & 84 & 86,6 \\
\hline SMA & 3 & 3,1 \\
DIPLOMA & 10 & 10,3 \\
S1 & & 68,0 \\
\hline Lama Bekerja & 66 & 11,3 \\
\hline 1 tahun & 11 & 6,2 \\
2 tahun & 6 & 7,2 \\
3 tahun & 7 & 2,1 \\
4 tahun & 2 & 5,2 \\
5 tahun & 5 &
\end{tabular}

Hasil dari Tabel 1 menunjukkan bahwa 97 responden berjenis kelamin laki-laki sebanyak 47 dan yang berjenis kelamin perempuan sebnayak 50. Usia $<20$ tahun sebanyak 39, usia 21-25 tahun sebanyak 52, usia 26-30 tahun sebanyak 3, usia 31-35 sebanyak 3. Pendidikan SMA sebanyak 84, diploma sebanyak 3, s1 sebanyak 10. Lama bekerja <1 tahun sebanyak 66, 1 tahun sebanyak 11,2 tahun sebanyak 6, 3 tahun sebanyak 7, 4 tahun sebanyak 2, 5 tahun sebanyak 5 .

\section{Hasil Uji Kualitas Data}

Tabel 2 Uji Validitas dan Uji Reliabilitas

\begin{tabular}{lllrlc}
\hline \multicolumn{2}{c}{ Kompensasi } & \multicolumn{2}{c}{ Budaya Organisasi } & \multicolumn{2}{c}{ Semangat Kerja } \\
\hline X1.1 & 0,591 & X2.1 & 0,661 & Y1 & 0,594 \\
X1.1 & 0,577 & X2.2 & 0,788 & Y2 & 0,806 \\
X1.3 & 0,870 & X2.3 & 0,821 & Y3 & 0,688 \\
X1.4 & 0,797 & X2.4 & 0,757 & Y4 & 0,634 \\
X1.5 & 0,852 & X2.5 & 0,839 & Y5 & 0,704 \\
X1.6 & 0,773 & X2.6 & 0,781 & & \\
X1.7 & 0,643 & X2.7 & 0,752 & & 0,761 \\
\hline \multicolumn{3}{r}{0,782} \\
\hline
\end{tabular}

Tabel diatas menunjukkan bahwa semua item pernyataan indikator dari variabel Kompensasi (X1) dan Budaya Organisas (X2) dan Semangat Kerja (Y) mempunyai nilai lebih besar dari $r$ tabel $(0,1663)$ dengan demikian semua item pernyataan untuk semua variabel dinyatakan valid.

Serta semua variabel Kompensasi (X1) dan Budaya Organisas (X2) dan Semangat Kerja (Y) memiliki nilai cronbach's alphalebih besar 0,6. Hal ini berarti bahwa alat ukur tersebut reliabel.

\section{Hasil Uji Asumsi Klasik}

Tabel 3 Asumsi Klasik

\begin{tabular}{ccccc}
\hline Variabel & Normalitas & \multicolumn{2}{c}{ Multikolonieritas } & Heteroskedastisitas \\
\hline & Sig & Tol & VIF & Sig \\
\hline Kompensasi & \multirow{2}{*}{0,200} & 0,474 & 2,111 & 0,809 \\
Budaya Organisasi & & 0,379 & 2,636 & 0,735 \\
\hline
\end{tabular}

Tabel 3menunjukkan model regresi tidak mengalami multikolonieritas (tolerance > 0,10 dan VIF < 10), tidak mengalami heteroskedastisitas dan data terdistribusi normal (Kolmogorov-Smirnovtest memiliki asymp sig >0,05). 


\section{Hasil Uji Hipotesis}

\section{Tabel 4 Hasil Uji Hipotesis}

\begin{tabular}{|c|c|c|c|c|c|c|}
\hline \multirow{2}{*}{\multicolumn{2}{|c|}{ Model }} & \multicolumn{2}{|c|}{$\begin{array}{l}\text { Unstandardized } \\
\text { Coefficients }\end{array}$} & \multirow{2}{*}{$\begin{array}{c}\text { Standardized } \\
\text { Coefficients } \\
\text { Beta }\end{array}$} & \multirow[b]{2}{*}{$\mathrm{t}$} & \multirow[b]{2}{*}{ Sig. } \\
\hline & & $\mathrm{B}$ & Std. Error & & & \\
\hline 1 & (Constant) & 5.321 & 1.492 & & 3.566 & .001 \\
\hline & TOTAL_X1 & .077 & .053 & .130 & 1.449 & .151 \\
\hline & TOTAL_X2 & .457 & .065 & .634 & 7.076 & .000 \\
\hline
\end{tabular}

Hasil pengujian hipotesis tabel 4 menunjukkan bahwa X1 menghasilkan t hitung 1.449 dengan tingkat signifikansi sebesar 0.151. Tingkat sifnifikansi tersebut lebih besar dari 0.05 berarti bahwa kompensasi tidak mempunyai pengaruh terhadap semangat kerja karyawan. X2 memiliki nilai t hitung sebesar 7.076 dan tingkat signifikansi 0.000 berarti bahwa budaya organisasi mempunyai pengaruh signifikan positif terhadap semangat kerja karyawan.

\section{PENUTUP}

\section{Kesimpulan}

Kompensasi tidak berpengaruh signifikan positif terhadap semangat kerja karyawan di Dazzle Accessories Yogyakarta. Hal ini ditunjukkan dengan variabel kompensasi memiliki nilai thitung lebih kecil dari nilai t-tabel, ini berarti bahwa kompensasi tidak mempunyai pengaruh terhadap semangat kerja karyawan. Hipotesis 1 ditolak.

Budaya organisasi berpengaruh signifikan positif terhadap semangat kerja karyawan di Dazzle Accessories Yogyakarta. Hal ini ditunjukkan dengan variabel budaya organisasi memiliki nilai $\mathrm{t}$ hitung lebih besar dari nila $\mathrm{t}$ tabel, ini berarti bahwa budaya organisasi mempunyai pengaruh positif terhadap semangat kerja karyawan. Hipotesis 3 diterima.

\section{Saran}

Berdasarkan hasil penelitian yang telah dilakukan, budaya organisasi adalah faktor yang berpengaruh signifikan positif terhadap semangat kerja karyawan, oleh karena itu Dazzle Accessories Yogyakarta harus lebih meningkatkan keramahan atasan kepada karyawan agar budaya organisasi semakin meningkat karena budaya organisasi berpengaruh tehadap semangat kerja.

Untuk penelitian selanjutnya perlu ditambahkan lagi variabel yang mempengaruhi semangat kerja karyawan.Disarankan untuk penelitian selanjutnya untuk menambah faktor lain yang sekiranya memperkuat semangat kerja. Misalnya gaya kepemimpinan, komuniaksidan lingkungan kerja. Hal ini dikarenakan variabel semangat kerja dipenelitian ini hanya mampu menjelaskan 50,8\% sedangkan, sisanya yaitu sebesar 49,2\% dipengaruhi oleh faktor lain.

\section{DAFTAR PUSTAKA}

Hartatik. (2014). Buku Praktis Mengembangkan SDM. Jogjakarta: Suka Buku. Hasibuan, M. (2012). Manajemen Sumber Daya Manusia. Jakarta: Pt. Bumi Aksara. Mangkunegara. (2005). Manajemen Sumber Daya Manusia. Jakarta: Bumi Angkara. Moekijat, 2006, Manajemen Kepegawaian (Personel Management), Alumni, Bandung. Nitisemito, A. (2010). Manajemen Personalia. Jakarta: Ghalia Indonesia.

Prijatna, T. I., \& Cahyaningrum, W. (2019). Pengaruh Budaya Organisasi Terhadap Semangat Kerja Dengan Kepuasan Kerja Sebagai Variabel Mediasi (Studi Pada Perum Lembaga Penyelenggaraan Pelayanan Navigasi Penerbangan Indonesia Cabang Tarakan). X, 7192. 
Robbins, Stephen P. 2012. Perilaku Organisasi. Edisi Kesepuluh, Jakarta: PT. Indeks Kelompok Gramedia.

Satriadi, Wahyunie, S., Marlinda, C., \& Ilyas, I. (2018). Pengaruh Kompensasi Terhadap Semangat Kerja Karyawan Ramayana Departement Store Cabang Kota Tanjungpinang. EJournal, 127-138.

Sugiyono. (2014). Metode Penelitian Pendidikan Pendekatan Kuantitatif, Kualitatif dan R\&D. Bandung: Alfabeta. 